\title{
Design of polyaspartic acid peptide-poly (ethylene glycol)-poly ( $\varepsilon$-caprolactone) nanoparticles as a carrier of hydrophobic drugs targeting cancer metastasized to bone
}

\author{
This article was published in the following Dove Press journal: \\ International Journal of Nanomedicine \\ 8 May 2017 \\ Number of times this article has been viewed
}

\author{
Jinsong Liu',* \\ Youyun Zengl,* \\ Shuai Shi ${ }^{2}$ \\ Lihua $\mathrm{Xu}^{3}$ \\ Hualin Zhang ${ }^{4}$ \\ Janak L Pathak ${ }^{5}$ \\ Yihuai Pan' \\ 'School and Hospital of Stomatology, \\ ${ }^{2}$ Institute of Biomedical Engineering, \\ School of Ophthalmology \& \\ Optometry and Eye Hospital, \\ Wenzhou Medical University, ${ }^{3}$ The \\ First Affiliated Hospital of Wenzhou \\ Medical University, Wenzhou, \\ ${ }^{4}$ College of Stomatology, Ningxia \\ Medical University, Yinchuan, ${ }^{5}$ School \\ of Pharmaceutical Science and \\ Technology, Health Sciences Platform, \\ Tianjin University, Tianjin, People's \\ Republic of China \\ *These authors contributed equally \\ to this work
}

Correspondence: Janak L Pathak School of Pharmaceutical Science and Technology, Health Sciences Platform, Tianjin University, Tianjin, People's Republic of China

Tel +86022 $2740 \quad 1105$

Email j.pathak@tju.edu.cn

Yihuai Pan

School and Hospital of Stomatology, Wenzhou Medical University, Wenzhou 325027, People's Republic of China Tel +865778806 6069 Email yihuaipan@dentist.an.cn

\begin{abstract}
Treatment of cancer metastasized to bone is still a challenge due to hydrophobicity, instability, and lack of target specificity of anticancer drugs. Poly (ethylene glycol)-poly ( $\varepsilon$-caprolactone) polymer (PEG-PCL) is an effective, biodegradable, and biocompatible hydrophobic drug carrier, but lacks bone specificity. Polyaspartic acid with eight peptide sequences, that is, (Asp) $)_{8}$, has a strong affinity to bone surface. The aim of this study was to synthesize (Asp) $)_{8}$-PEG-PCL nanoparticles as a bone-specific carrier of hydrophobic drugs to treat cancer metastasized to bone. ${ }^{1} \mathrm{H}$ nuclear magnetic resonance, Fourier transform infrared spectroscopy, and transmission electron microscopy data showed that (Asp) - $_{8}$-PEG-PCL nanoparticles (size $100 \mathrm{~nm}$ ) were synthesized successfully. (Asp) $)_{8}$-PEG-PCL nanoparticles did not promote erythrocyte aggregation. Fluorescence microscopy showed clear uptake of Nile red-loaded (Asp) $)_{8}$-PEG-PCL nanoparticles by cancer cells. (Asp) $)_{8}$-PEG-PCL nanoparticles did not show cytotoxic effect on MG63 and human umbilical vein endothelial cells at the concentration of $10-800 \mu \mathrm{g} / \mathrm{mL}$. (Asp) $)_{8}$-PEG-PCL nanoparticles bound with hydroxyapatite 2-fold more than PEG-PCL. Intravenously injected (Asp) $)_{8}$-PEG-PCL nanoparticles accumulated 2.7-fold more on mice tibial bone, in comparison to PEG-PCL. Curcumin is a hydrophobic anticancer drug with bone anabolic properties. Curcumin was loaded in the (Asp) $)_{8}$-PEG-PCL. (Asp) $)_{8}$-PEGPCL showed $11.07 \%$ loading capacity and $95.91 \%$ encapsulation efficiency of curcumin. The

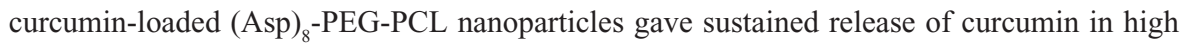
dose for $>8$ days. The curcumin-loaded (Asp) $)_{8}$-PEG-PCL nanoparticles showed strong antitumorigenic effect on MG63, MCF7, and HeLa cancer cells. In conclusion, (Asp) $)_{8}$-PEG-PCL nanoparticles were biocompatible, permeable in cells, a potent carrier, and an efficient releaser of hydrophobic anticancer drug and were bone specific. The curcumin-loaded (Asp) $)_{8}$-PEG-PCL nanoparticles showed strong antitumorigenic ability in vitro. Therefore, (Asp) $)_{8}$-PEG-PCL nanoparticles could be a potent carrier of hydrophobic anticancer drugs to treat the cancer metastasized to bone.
\end{abstract}

Keywords: bone-targeting nanoparticles, polyaspartic acid peptides, PEG-PCL, cancer metastasized to bone, hydrophobic anticancer drug, curcumin

\section{Introduction}

Bone metastasis is a frequent complication in advanced stage of certain cancers such as breast, prostate, uterine, kidney, and lung cancer. ${ }^{1-4}$ About $80 \%$ patients with advanced breast and prostate cancer have incurable bone metastasis. ${ }^{5,6}$ Once cancer cells metastasize in bone, high concentration of growth factors and cytokines in the 
bone microenvironment provide a fertile soil for tumor propagation. ${ }^{3,7}$ Cancer bone metastasis not only accelerates tumor propagation but also causes osteolysis and metabolic disturbances leading to hypercalcemia and acid/base imbalance. ${ }^{3}$ Cancer bone metastases are associated with significant morbidity including immobility, pain, and the development of bone-related pathologic fractures, and spinal cord compression. ${ }^{8}$ Due to the anatomic location, the delivery of appropriate dose of chemotherapy and radiotherapy targeting the tumor in bone niche is still a challenge. Due to less vascularization, only $7 \%$ of the cardiac output goes to the bone versus $30 \%$ to the liver. ${ }^{9}$ Therefore, intravenously administered anticancer chemotherapeutics do not achieve enough of a therapeutic dose at bone metastatic sites to suppress tumor growth. A majority of the intravenously administered drug is either excreted and/or metabolized, or accumulates in other, more highly perfused body compartments or tissues prior to reaching bone niche in sufficient doses. Bone-targeted therapy, such as the bisphosphonate and denosumab, is used to prevent the skeletal-related effects during cancer bone metastasis. ${ }^{10}$ However, this therapy cannot inhibit tumor progression and also poses adverse effects. Hydrophobic nature and poor stability of anticancer drugs are the main challenges to deliver them to the bone niche targeting metastasized tumor colony. Therefore, novel antitumor therapeutic approaches using bone-specific nanoparticles, which can deliver hydrophobic anticancer drugs with minimum adverse effects, targeting the tumor colony hiding in bone niche are desperately needed.

Series of block copolymers based on poly (ethylene glycol)poly ( $\varepsilon$-caprolactone) (PEG-PCL) encapsulate hydrophobic drugs with high stability and bioavailability. ${ }^{11-13}$ PEG-PCL polymers are highly biodegradable and biocompatible. ${ }^{11,13}$ Therefore, PEG-PCL polymers have been widely used as hydrophobic drug delivery systems. ${ }^{11-14}$ PEG-PCL lacks bone specificity and cannot deliver drugs targeting the tumor metastasized in the bone niche. Therefore, bone-specific moietylinked PEG-PCL nanoparticles might be a suitable carrier of hydrophobic anticancer drugs targeting bone niche. Various tetracyclines and bisphosphonates have been frequently used as bone-targeting moieties in nanotechnology-based therapy, but limitations related to these drugs remain. ${ }^{15,16}$ Tetracycline binds mainly with less-crystalline hydroxyapatites (newly forming bone), ${ }^{17}$ and long-term use of bisphosphonate increases the risk of osteonecrosis in the jaw. ${ }^{18} \mathrm{~A}$ short peptide sequence of repetitive aspartic acid (4-10 amino acids) has been shown to interact exclusively with bone in vitro and in vivo. ${ }^{19-22}$ (Asp) ${ }_{8}$ is biodegradable, biocompatible, and has shown strong affinity to more crystalline hydroxyapatite and bone surface. ${ }^{19,21,22}$ Therefore, (Asp) ${ }_{8}$-linked PEG-PCL nanoparticles can be a potent hydrophobic anticancer drug carrier targeting the bone niche.

Available chemotherapeutics such as alkylating agents, antimetabolites, and drugs targeting specific signal transduction can significantly inhibit the tumor growth, but due to inappropriate doses that reach the tumor site, they often suffer from multidrug resistance. ${ }^{23}$ Delivery of anticancer drugs to tumor metastasized bone niche in appropriate dose is still a big challenge due to hydrophobicity, instability, and lack of target specificity of anticancer drugs. Curcumin (diferuloylmethane) is a polyphenol compound derived from the roots of Curcuma longa, which inhibits the growth and metastasis of a wide variety of tumor cells including multidrug-resistant tumor. ${ }^{24-27}$ Curcumin has shown bone anabolic properties, but lacks bone specificity. ${ }^{28}$ Curcumin is hydrophobic, highly instable in vivo, and has poor bioavailability. ${ }^{29}$ Therefore, it could be used as a hydrophobic drug model to test the efficacy of bone-specific amphiphilic nanoparticles. Current researches are focused on the development of potential drug delivery systems to increase the aqueous solubility, stability, as well as the bioavailability of curcumin. ${ }^{30-32}$ (Asp) ${ }_{8}$-linked PEG-PCL copolymers that can self-assemble into nanoparticles in aqueous medium with a drug-loading hydrophobic core and a hydrophilic shell could be a bone-specific carrier of hydrophobic anticancer drugs.

In this study, we aimed to design (Asp) -linked PEG-PCL nanoparticles as a carrier of hydrophobic drugs to treat cancer bone metastasis, as shown in Figure 1. (Asp) has bonespecific affinity and PEG-PCL can carry hydrophobic drugs. (Asp) $)_{8}$-PEG-PCL nanoparticles were synthesized and characterized. Biocompatibility, hemolytic effect, cellular uptake, hydroxyapatite binding affinity, accumulation in bone niche, curcumin loading and releasing rate, and stability of (Asp) $)_{8}^{-}$ PEG-PCL nanoparticles were tested. The curcumin-loaded (Asp) $)_{8}$-PEG-PCL nanoparticles showed strong antitumorigenic ability in vitro. Therefore, (Asp) ${ }_{8}$-PEG-PCL could be a novel bone-specific carrier of hydrophobic anticancer drugs that helps in treating the cancer metastasized to bone.

\section{Materials and methods Materials}

We used maleimide terminated poly (ethylene glycol) or MAL-PEG-MAL (Mw =5,000 Da; Shanghai Yarebio Co Ltd, Shanghai, People's Republic of China), $\varepsilon$-caprolactone 


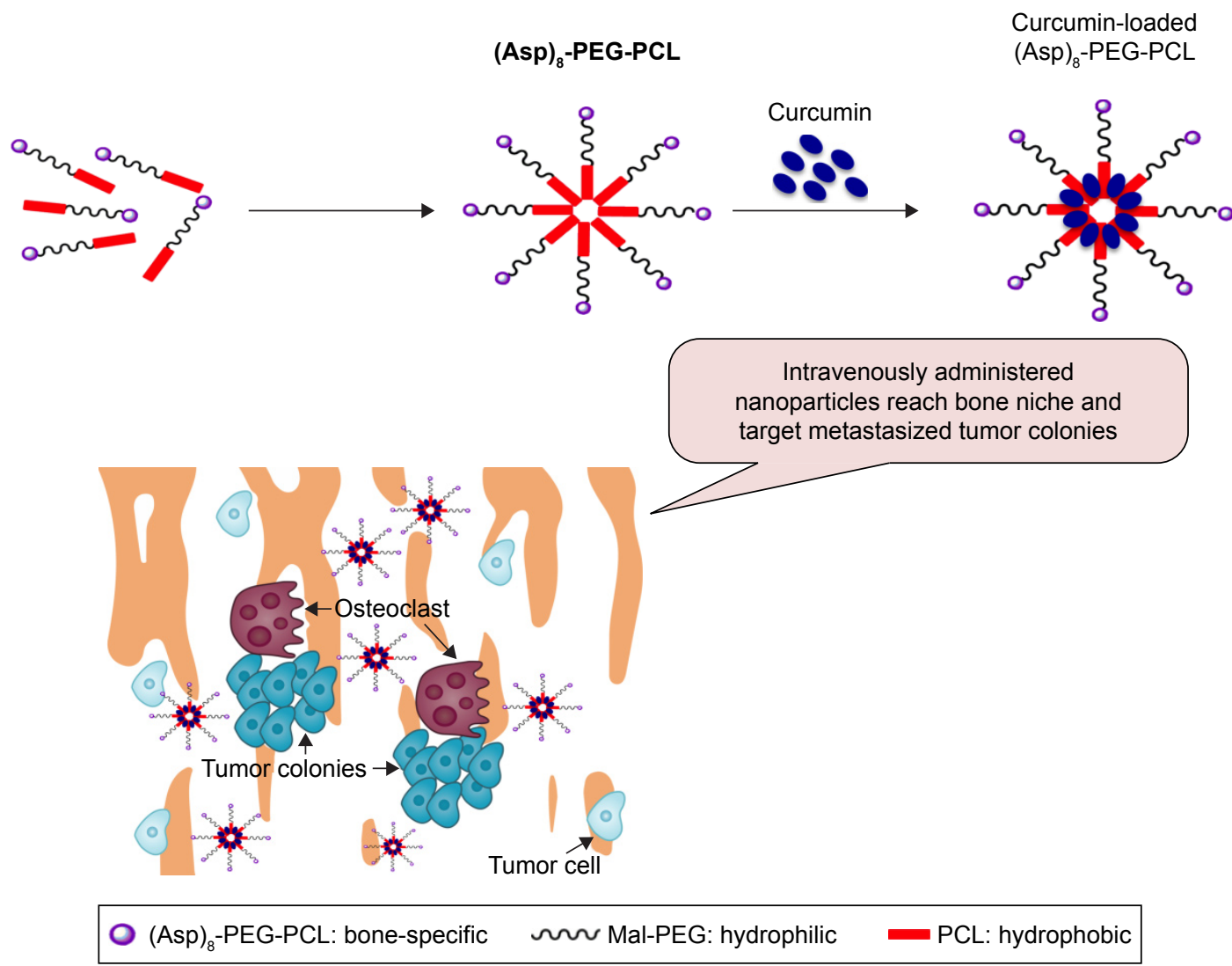

Figure I Amphiphilic (Asp) $)_{8}$-PEG-PCL nanoparticles have been designed for curcumin delivery targeting cancer metastasized to bone. Abbreviations: (Asp) $)_{8}^{-P E G-P C L, ~ p o l y a s p a r t i c ~ a c i d ~ p e p t i d e s-p o l y ~(e t h y l e n e ~ g l y c o l)-p o l y ~(\varepsilon-c a p r o l a c t o n e) ~ p o l y m e r ; ~ M a l-P E G, ~ m a l e i m i d e ~ t e r m i n a t e d ~ p o l y e t h y l e n e ~ g l y c o l ; ~}$ $\mathrm{PCL}$, poly $\varepsilon$-caprolactone.

$(\varepsilon-C L, M w=114$ Da; Alfa Aesar, MA, USA), stannous octoate (Sn(Oct) $)_{2}$; Sigma Aldrich, St Louis, MO, USA), 97\% glycidyl methacrylate (GMA; Sigma Aldrich, USA), ethanol, methanol, petroleum ether (Sinopharm Chemical Reagent Co., Ltd, Shanghai, People's Republic of China), aspartic acid oligopeptides (eight repeating sequences of aspartate (Asp); ${ }_{8}$ ChinaPeptides Co., Ltd, Shanghai, People's Republic of China), xylenol orange disodium salt (XO, Sigma Aldrich, USA), and 6-hydroxycoumarin (coumarin; Dalian Meilun Biotech Co., Ltd, Dalian, People's Republic of China).

\section{Cell culture and animal study}

The MG63 osteosarcoma cell line, MCF7 breast cancer cell line, and human umbilical vein endothelial cells were purchased from American Type Culture Collection (ATCC, Rockville, MD, USA). BALB/c female mice (6-8 weeks old) and Sprague Dawley female rats (3 months old) were purchased from the Shanghai SLAC Laboratory Animal Co. Ltd (Shanghai, People's Republic of China). The animal care and all animal experimental procedures were conducted in accordance with the ethical standards of Wenzhou Medical University Animal Care and Use Committee guidelines. Animal study protocol was approved by the Animal Experimental Ethical Panel of Wenzhou Medical University (ID Number: wydw2015-0019).

\section{Synthesis of (Asp) $)_{8}$-PEG-PCL nanoparticles}

(Asp) $)_{8}$-PEG-PCL copolymer was synthesized in two steps (Figure 1): 1) MAL-PEG-PCL block copolymer was first synthesized through ring-opening polymerization of $\varepsilon-C L$ and MAL-PEG in the presence of $\mathrm{Sn}(\mathrm{Oct})_{2}$ at $130^{\circ} \mathrm{C}$, as described previously. ${ }^{14}$ The product was collected by purification through dialysis and lyophilization. 2) (Asp) - $_{8}$-PEG-PCL nanoparticles were synthesized by dissolving (Asp) ${ }_{8}$ and MAL-PEG-PCL in 2:1 molar ratio in phosphate-buffered saline (PBS) by stirring at room temperature for $24 \mathrm{~h}$. The obtained product was extracted and dialyzed against distilled water for 2 days. Finally, the product was lyophilized and stored in a tower drier before use. 
'H nuclear magnetic resonance (NMR), Fourier transform infrared (FTIR) spectroscopy, transmission electron microscopy (TEM), and particle size measurement of (Asp) $)_{8}$-PEG-PCL nanoparticles

${ }^{1} \mathrm{H}$ NMR and FTIR spectroscopy were used to confirm the chemical composition and molecular weight of the (Asp) ${ }_{8}^{-}$ PEG-PCL nanoparticles. ${ }^{1} \mathrm{H}$ NMR spectra (in dimethyl sulfoxide) were recorded using a $500 \mathrm{MHz}$ Bruker Avance III spectrometer (Bruker Optik GmbH, Ettlingen, Germany). FTIR spectra were obtained using a Thermo Fisher Nicolet 6700 FTIR spectrophotometer (Thermo Fisher Scientific, Waltham, MA, USA).

Particle size distribution of the (Asp) $)_{8}$-PEG-PCL nanoparticles was determined by Malvern Zetasizer Nano-ZS Zen 3600 (Malvern, Worcestershire, UK) particle size analyzer. The sample was diluted with distilled water and detected at $25^{\circ} \mathrm{C}$. All these measurements were run at least three times with independent particle batches. Morphology of the (Asp) ${ }_{8}^{-}$ PEG-PCL was characterized by a TEM (Tecnai F20; FEI, NJ, USA). The sample was diluted with distilled water and placed on a copper grid covered with nitrocellulose. Before observation, the sample was negatively stained with phosphotungstic acid $(0.5 \% ; \mathrm{w} / \mathrm{v})$ for $5 \mathrm{~min}$ and dried at room temperature.

\section{Hemocompatibility assay}

Intravenously administered nanoparticles should be hemocompatible, that is, nanoparticles should not hemolyze and/or aggregate the erythrocytes and other blood cells. ${ }^{33} \mathrm{We}$ tested the hemocompatibility of (Asp) $)_{8}$-PEG-PCL on rabbit erythrocytes. Rabbit erythrocyte suspension (2\%) was prepared in saline solution. PEG-PCL or (Asp) ${ }_{8}$-PEG-PCL $(0.5 \mathrm{mg} / \mathrm{mL})$ was added to the erythrocyte suspension and incubated for $30 \mathrm{~min}$ at $37^{\circ} \mathrm{C}$. Erythrocyte aggregation was observed under optical microscope at $40 \times$ magnification.

\section{Cytotoxicity assay}

The nanoparticles for in vivo administration targeting the cancer cells should be biocompatible, that is, such nanoparticles should not be toxic to the human cells. Cytotoxicity of (Asp) -PEG-PCL was evaluated by 3-(4,5-dimethylthiazol-2yl)-2,5-diphenyltetrazolium bromide (MTT) assay. PEG-PCL was used as a control, since it is reported as a biocompatible polymer. ${ }^{34}$ MG63 osteosarcoma cell line and human umbilical vein endothelial cells were seeded in 96-well plates at 5,000 cells/well. After $24 \mathrm{~h}$, the medium was replaced with fresh medium containing (Asp) ${ }_{8}$-PEG-PCL or mPEG-PCL nanoparticles $(10-800 \mu \mathrm{g} / \mathrm{mL})$. Cultures were incubated with nanoparticles for $24 \mathrm{~h}$, and then $20 \mu \mathrm{L}$ of MTT solution $(5 \mathrm{mg} / \mathrm{mL})$ was added. Cultures were incubated with MTT solution for $4 \mathrm{~h}$ at $37^{\circ} \mathrm{C}$. The MTT solution was carefully removed, and $150 \mu \mathrm{L}$ of dimethyl sulfoxide was added to each well. The absorbance was measured at $490 \mathrm{~nm}$ using an enzyme-linked immunosorbent assay microplate reader (Bio-Rad Laboratories Inc., Hercules, CA, USA).

\section{Cellular uptake study}

MG63 osteosarcoma cell line was used for cellular uptake study. First, the cells were seeded in a six-well cell culture plate with a cell density of $1 \times 10^{5}$ cells/well and incubated at $37^{\circ} \mathrm{C}$ for $24 \mathrm{~h}$. The cultures were incubated with $100 \mu \mathrm{g} / \mathrm{mL}$ of Nile red-loaded (Asp) $)_{8}$-PEG-PCL nanoparticles dissolved in PBS solution at $37^{\circ} \mathrm{C}$ for $4 \mathrm{~h}$. After that, the treated cells were carefully washed with PBS (three times). Then the cells were stained with Hoechst, visualized, and imaged using an inverted fluorescence microscope (Nikon C-HGFI; Nikon Corporation, Tokyo, Japan).

\section{In vitro hydroxyapatite binding assay}

Human bone consists of about $70 \%$ (by weight) of hydroxyapatite in different modified form.

Binding affinity of the (Asp) $)_{8}$-PEG-PCL nanoparticles to hydroxyapatite was evaluated as described previously. ${ }^{35}$ Briefly, hydroxyapatite was suspended in ultrapure water at a concentration of $5 \mathrm{mg} / \mathrm{mL}$. Hydrophobic fluorescent Nile red added PEG-PCL or (Asp) $)_{8}$-PEG-PCL (the weight ratio is $1: 10$ ) was added to the crystallized hydroxyapatite suspensions and mixed at room temperature by rotating for $24 \mathrm{~h}$. The mixture was shaken for $30 \mathrm{~min}, 1 \mathrm{~h}, 2 \mathrm{~h}, 7 \mathrm{~h}$, and $24 \mathrm{~h}$, respectively. After centrifugation at $10,000 \mathrm{rpm}$ for $5 \mathrm{~min}$, the fluorescence intensity of the supernatant was measured with Ulrospec 7000 (GE Healthcare Bio-Sciences Corp., Piscataway, NJ, USA). The decrease in intensity corresponds to the initial fluorescence emission intensity expressed by the amount of Nile red/nanoparticles bound to hydroxyapatite, as calculated from the formula given below:

HAP adsorption affinity

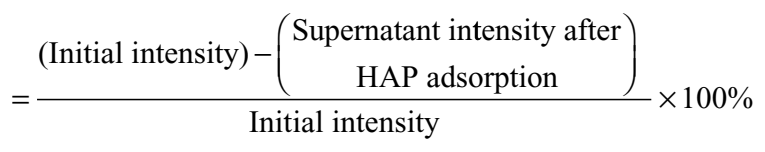

Accumulation of intravenously administered (Asp) ${ }_{8}$-PEG-PCL nanoparticles in bone niche

Near-infrared lipophilicity fluorescence dye (Cy7; Sigma Aldrich, USA)-linked (Asp) ${ }_{8}$-PEG-PCL or PEG-PCL 
nanoparticle was used to analyze in vivo bone-specific affinity. Eight BALB/c mice were divided into the following four groups: 1) saline, 2) Cy7, 3) Cy7-linked PEG-PCL, and 4) Cy7-linked

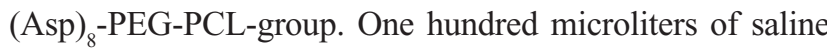
solution, free CY7, CY7-linked PEG-PCL, or CY7-linked (Asp) $)_{8}$-PEG-PCL was injected into mice of each group through the tail vein. The mice were sacrificed after $24 \mathrm{~h}$ and the femur and tibia were collected. The fluorescence signal $(430-820 \mathrm{~nm})$ was detected in bone using in vivo imaging systems (IVIS 200 Imaging System; Caliper Life Sciences, Alameda, CA, USA).

Green fluorochrome coumarin-loaded PEG-PCL or (Asp) $)_{8}$-PEG-PCL was used for histologic analysis of in vivo bone specificity. Red fluorochrome XO was used to label new bone deposition at bone formation surfaces. ${ }^{36}$ Nine Sprague Dawley rats (3 months old, female) were divided into three groups: 1) XO and coumarin, 2) XO and coumarin-loaded PEG-PCL, and 3) XO and coumarin-loaded (Asp) ${ }_{8}$-PEG-PCL group. XO (30 mg/kg) was injected into rats subcutaneously 3 days prior to the administration of coumarin or coumarinloaded nanoparticles. Coumarin or coumarin-loaded nanoparticles $(30 \mathrm{mmol} / \mathrm{kg}$ in $0.3 \mathrm{~mL}$ saline) were administered to the rats through the tail vein. After $24 \mathrm{~h}$ of administration, the rats were sacrificed, tibias were immersed in $70 \%$ ethanol, and frontal sections of tibia (15 mm thickness) were obtained using EXAKT E300CP microtome (EXAKT Vertriebs, Norderstedt, Germany) as described previously. ${ }^{37}$ Thereafter, the fluorescence intensity of coumarin was visualized using a confocal microscope (A1 plus; Nikon Instruments Europe B.V., Kingston upon Thames, UK). Integrated optical density of the coumarin labeled on bone section was quantified by using Image-Pro Plus 6.0 software.

\section{Curcumin loading in the (Asp) $)_{8}$-PEG-PCL nanoparticles}

Curcumin was loaded in (Asp) , $_{8}$-PEG-PCL by a single-step self-assembly method. ${ }^{38}$ Briefly, $10 \mathrm{mg}$ of blank copolymer and $1 \mathrm{mg}$ curcumin powder were first suspended into $1 \mathrm{~mL}$ of acetone, respectively. The acetone solution of curcumin was added to the (Asp) $)_{8}$-PEG-PCL solution drop by drop and stirred for $20 \mathrm{~min}$ at room temperature. The solution was transferred to a round-bottomed flask to evaporate acetone with a rotary evaporator. Finally, distilled water was added to redissolve the drug, and the product was lyophilized.

\section{Curcumin loading capacity and encapsulation efficiency of (Asp) ${ }_{8}$-PEG- PCL nanoparticles}

The drug encapsulation efficiency of curcumin-loaded (Asp) PEG-PCL nanoparticles was measured by high-performance liquid chromatography (HPLC) as described previously. ${ }^{39}$ Briefly, $10 \mathrm{mg}$ of lyophilized powder was dissolved in distilled water solution to obtain the curcumin-loaded

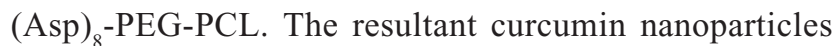
were centrifuged at $18,000 \mathrm{rpm}$ for $30 \mathrm{~min}$ to obtain the nanoparticle sheet. The nanoparticle sheet was resuspended into distilled water to form a homogeneous micellar solution and the curcumin concentration was measured by HPLC. During HPLC, methanol $/ 0.3 \%$ acetic water solution $(80: 20, \mathrm{v} / \mathrm{v})$ was used as the mobile phase with a flow rate of $1.0 \mathrm{~mL} / \mathrm{min}$, filtered through a $0.22 \mu \mathrm{m}$ Millipore filter, and degassed prior to use. The analysis was performed on a reversed-phase $\mathrm{C} 18$ column $(4.6 \times 150 \mathrm{~mm}$, particle size $5 \mu \mathrm{m}$, SunFire Analysis column). The retention time of analysis was $12 \mathrm{~min}$ and the sample injection volume was $20 \mu \mathrm{L}$. The eluent was detected by Waters photodiode array (PDA) detector at $420 \mathrm{~nm}$.

Drug loading capacity and drug encapsulation efficiency were calculated by the following formulae:

$$
\begin{gathered}
\begin{array}{c}
\text { Drug encapsulation } \\
\text { efficiency }(\%)
\end{array}=\frac{\text { Curcumin micelles }}{\text { Total curcumin }} \times 100 \\
\text { Drug loading capacity }(\%)=\frac{\text { Curcumin micelles }}{\text { Dried particle weight }} \times 100
\end{gathered}
$$

\section{In vitro curcumin release profile}

Curcumin release behavior of the curcumin-loaded nanoparticles was tested in vitro as described previously. ${ }^{39}$ Briefly, $1 \mathrm{~mL}$ of native curcumin or curcumin-loaded nanoparticles was transferred into a dialysis bag (molecular weight cutoff, 3,500 $\mathrm{Da}$, dialysis area about $1 \mathrm{~cm}^{2}$ ) followed by immersion into $10 \mathrm{~mL}$ PBS (pH 7.4) solution containing $0.5 \%$ Tween $20(\mathrm{w} / \mathrm{v})$ at $37^{\circ} \mathrm{C}$ with gentle stirring at $100 \mathrm{rpm} / \mathrm{min}$. One milliliter of the released medium was collected at predetermined time points. The concentration of curcumin released was analyzed by HPLC as described above (in the "Curcumin loading capacity and encapsulation efficiency of (Asp) $)_{8}$-PEG-PCL nanoparticles" section).

\section{Stability of curcumin-loaded (Asp) ${ }_{8}$-PEG- PCL nanoparticles}

(Asp) $)_{8}$-PEG-PCL and curcumin-loaded (Asp) $)_{8}$-PEG-PCL nanoparticles were diluted with $0.9 \%$ normal saline (NS) and $10 \%$ fetal bovine serum in NS. To test the hydrodynamic diameter changes, the size of nanoparticles was measured every $6 \mathrm{~h}$ using Malvern Zetasizer Nano-ZS Zen 3600 (Malvern). 


\section{In vitro antitumorigenic effect of curcumin-loaded (Asp) ${ }_{8}$-PEG-PCL nanoparticles}

In vitro antitumorigenic effect of native curcumin, $(\mathrm{Asp})_{8}^{-}$ PEG-PCL, or curcumin-loaded (Asp) 8 -PEG-PCL against various cancer cell lines was tested by MTT assay. MCF7 breast cancer cell line, Mg63 osteosarcoma cell line, or HeLa cervical cancer cell line was seeded in 96-well plates with a density of $1 \times 10^{4}$ cells/well and incubated at $37^{\circ} \mathrm{C}$ for $24 \mathrm{~h}$. Ten microliters of either native curcumin dissolved in dimethyl sulfoxide, (Asp) $)_{8}$-PEG-PCL, or curcumin-loaded (Asp) $)_{8}$-PEG-PCL nanoparticles was added to the cultures and incubated again for $24 \mathrm{~h}$. The effect of treatments was measured by MTT assay as described above (in the "Cytotoxic effect" section).

\section{Statistical analysis}

The results were reported as the mean \pm standard deviation. Statistical analysis was performed by one-way analysis of variance. Values of $P<0.05$ were considered to be significant.

\section{Results \\ Synthesis and characterization of (Asp) $)_{8}$-PEG-PCL nanoparticles}

(Asp) - $_{8}$-PG-PCL was successfully synthesized by direct conjugation of the MAL-PEG, PCL, and (Asp)-Cys, as described in Figure 2A. The chemical composition of the

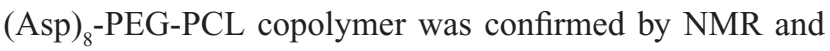
FTIR (Figures $2 \mathrm{~B}$ and $3 \mathrm{~A}$ ). The characteristic ${ }^{1} \mathrm{H}$ NMR peak for (Asp) ${ }_{8}$ appeared at $0.85 \mathrm{ppm}$ (corresponds to $-\mathrm{CH}_{2}-\mathrm{CH}-$; Figure 2B). Peaks near $3.99 \mathrm{ppm}$ (correspond to $-\mathrm{CH}_{2} \mathrm{CH}_{2} \mathrm{O}$ ) and $3.5 \mathrm{ppm}$ (correspond to $-\mathrm{CH}_{2} \mathrm{OOC}-$ ) were attributed to PEG and PCL, respectively (Figure 2B). We successfully synthesized PEG-PCL copolymer by ring-opening copolymerization of Mal-PEG and $\varepsilon$-CL (Figure 2A). As illustrated in Figure $3 \mathrm{~A},(\mathrm{Asp})_{8}$-PEG-PCL exhibits characteristic peaks of PEG-PCL near $2,700 \mathrm{~cm}^{-1}$ and a peak of (ASP) ${ }_{8}$ near $1,600 \mathrm{~cm}^{-1}$. As observed in Figure 3B, (Asp) $)_{8}$-PEG-PCL exhibited a narrow size distribution with an average diameter of $100 \mathrm{~nm}$. (Asp) $)_{8}$-PEG-PCL nanoparticles were all spherical or spherical-like particles and uniform in size and shape, as shown in TEM image (Figure 3C).

A
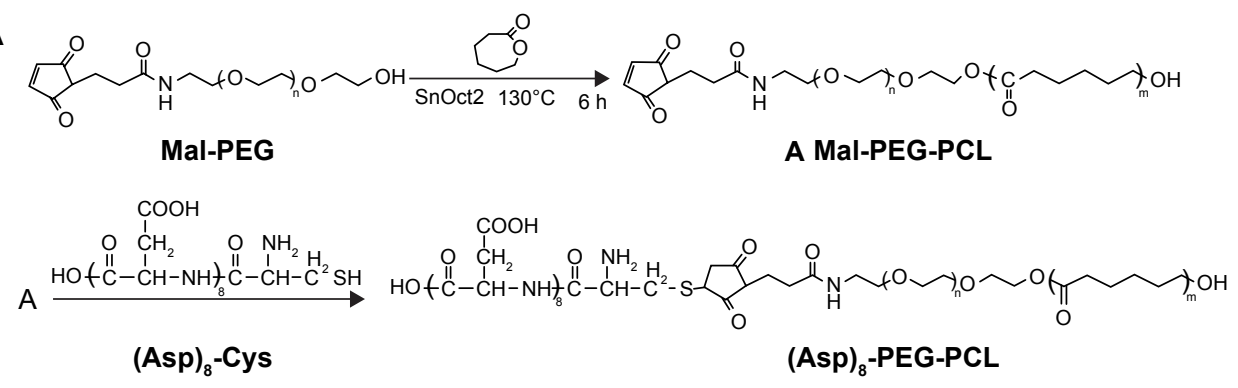

B

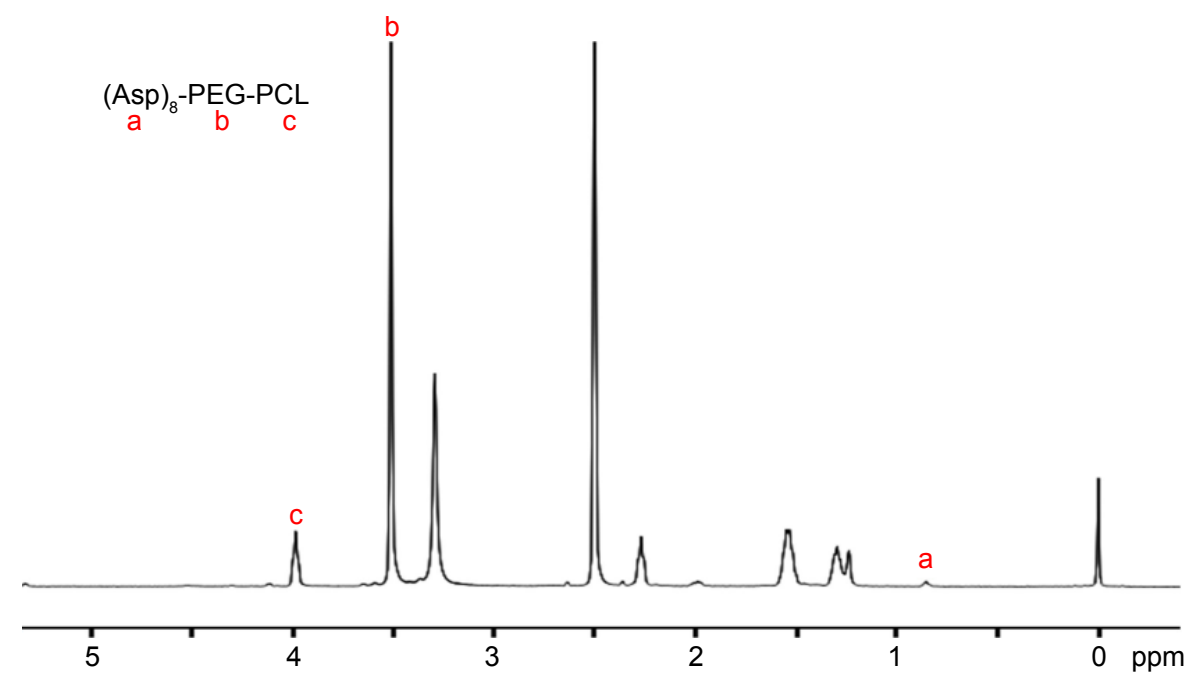

Figure 2 Synthesis and characterization of the (Asp) $)_{8}$-PEG-PCL nanoparticles.

Notes: (A) Schematic illustration of self-assembled (Asp) $)_{8}$-PEG-PCL nanoparticles. (B) 'H NMR spectrum of the (Asp) ${ }_{8}$-PEG-PCL nanoparticles.

Abbreviations: (Asp) $)_{8}$-Cys, polyaspartic acid peptides linked with cysteine; (Asp) $)_{8}$-PEG-PCL, polyaspartic acid peptides-poly (ethylene glycol)-poly ( $(\varepsilon$-caprolactone) polymer; Mal-PEG, maleimide terminated polyethylene glycol; NMR, nuclear magnetic resonance; PCL, poly $\varepsilon$-caprolactone. 

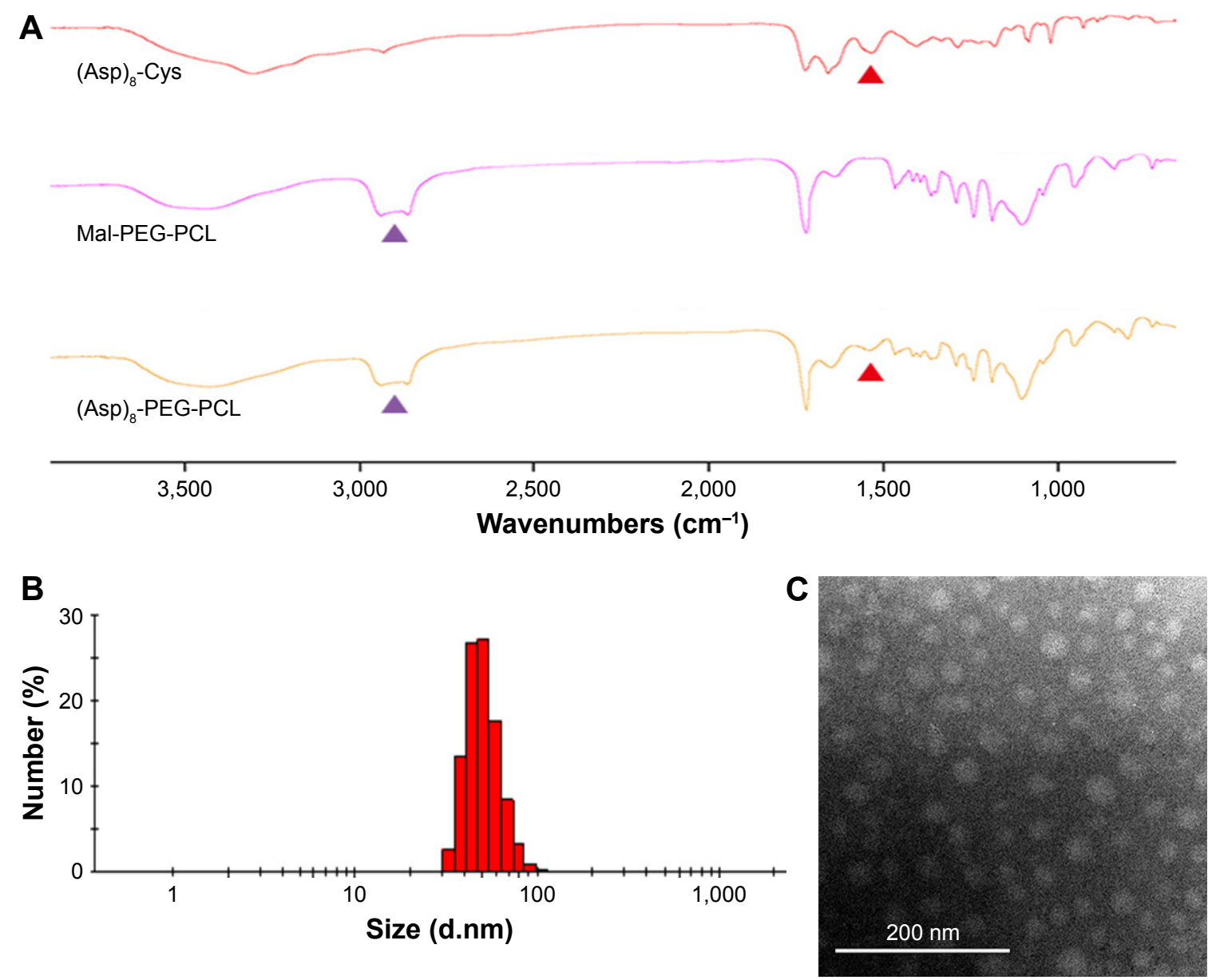

Figure 3 Physicochemical characterization of the (Asp) - PEG-PCL nanoparticles.

Notes: (A) FTIR spectra of (Asp) ${ }_{8}$-Cys, Mal-PEG-PCL, and (Asp) $)_{8}$-PEG-PCL. (B) The particle size distribution of the (Asp) $)_{8}$-PEG-PCL nanoparticles analyzed by nanoparticle size analyzer. (C) Particle size morphology of the (Asp) $)_{8}$ PEG-PCL nanoparticles analyzed by TEM. Red arrow indicates (Asp) $)_{8}$ specific spectra and purple arrow indicates PEG-PCL specific spectra.

Abbreviations: (Asp) $)_{8}$-Cys, poly-aspartic acid peptides link with cysteine; (Asp) $)_{8}$-PEG-PCL, polyaspartic acid peptides-poly (ethylene glycol)-poly ( $\varepsilon$-caprolactone) polymer; FTIR, Fourier transform infrared; Mal-PEG, maleimide terminated polyethylene glycol; PCL, poly \&-caprolactone; TEM, transmission electron microscopy.

\section{Hemocompatibility, biocompatibility, and cellular uptake assay}

The degree of erythrocyte aggregation indicates the blood compatibility of nanoparticles. The concentration of both PEG-PCL and (Asp) $)_{8}$-PEG-PCL at $0.5 \mathrm{mg} / \mathrm{mL}$ did not enhance erythrocyte aggregation (Figure 4A-C). Erythrocyte morphology in all groups was similar, showing no hemolytic effect of the treatments (Figure 4). (Asp) $)_{8}$-PEG-PCL showed no effect on HUVEC (noncancer cells) and MG63 cells (cancer cell line) viability at $10-800 \mu \mathrm{g} / \mathrm{mL}$ concentration (Figure 5A and B). The cellular uptake of Nile red-loaded (Asp) $)_{8}$-PEG-PCL by MG63 tumor cells was examined.
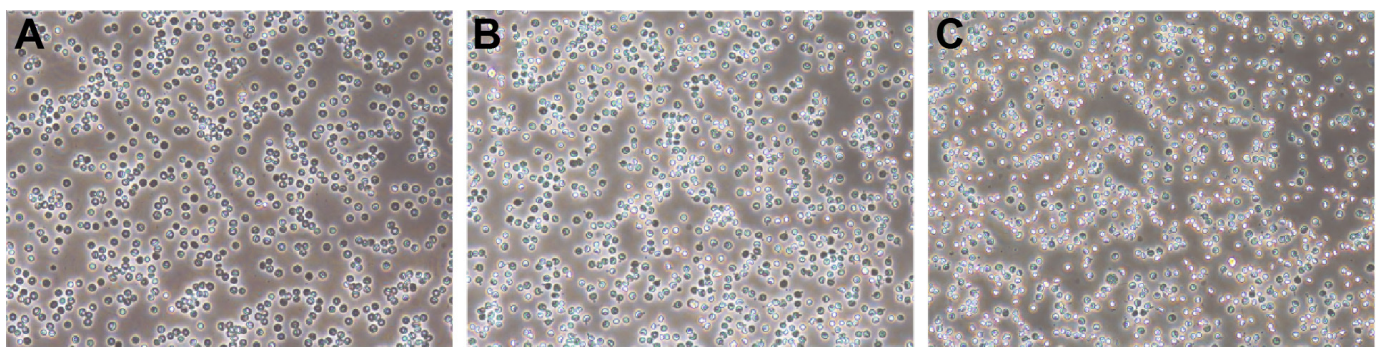

Figure 4 Microscopic images of erythrocyte aggregation (I0X).

Notes: (A) Normal saline used as control; (B) the PEG-PCL nanoparticles, $0.5 \mathrm{mg} / \mathrm{mL}$; (C) the (Asp) ${ }_{8}-\mathrm{PEG}-\mathrm{PCL}$ nanoparticles, $0.5 \mathrm{mg} / \mathrm{mL}$.

Abbreviation: (Asp) $)_{8}$-PEG-PCL, polyaspartic acid peptides-poly (ethylene glycol)-poly ( $\varepsilon$-caprolactone) polymer. 

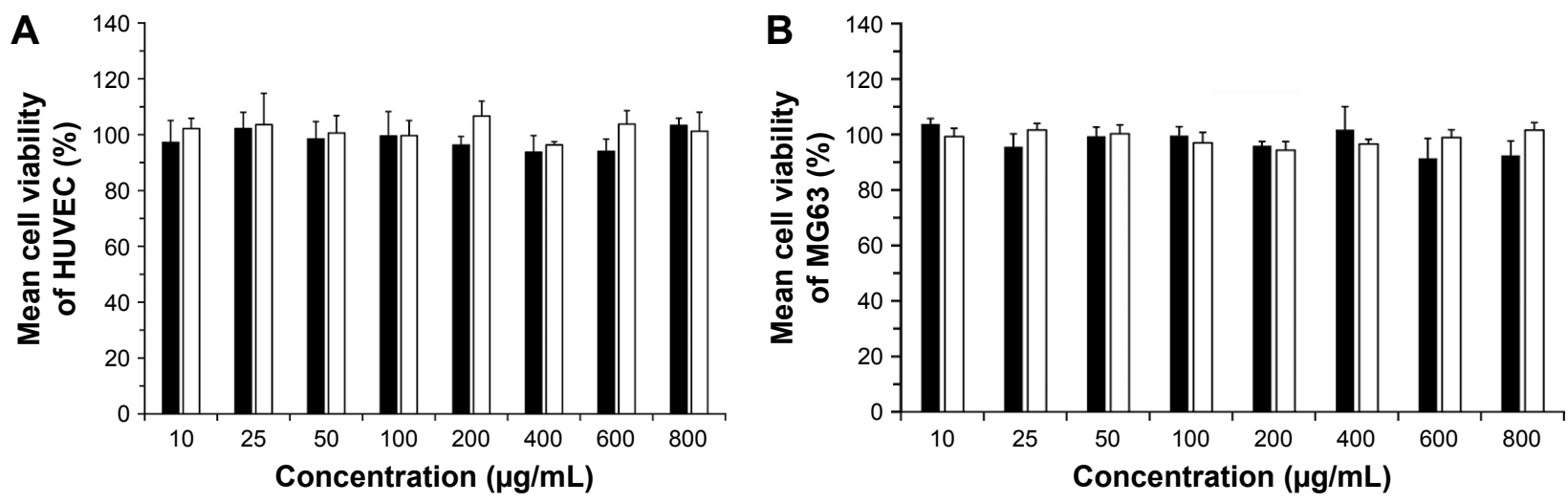

(Asp) $)_{8}$-PEG-PCL $\square$ PEG-PCL

Figure 5 Cytotoxicity of the (Asp) $)_{8}$-PEG-PCL nanoparticles on (A) HUVEC and (B) MG63 cells.

Abbreviations: (Asp) $)_{8}$-PEG-PCL, polyaspartic acid peptides-poly (ethylene glycol)-poly ( $\varepsilon$-caprolactone) polymer; HUVEC, human umbilical vein endothelial cells.

Blank (nonlabeled) empty nanoparticles exhibited no fluorescence, similar to that of nontreated cells (figure not shown), and was determined as the background for further analysis. (Asp) $)_{8}$-PEG-PCL nanoparticles accumulated and were clearly visualized in the cellular cytoplasm from 1 to $24 \mathrm{~h}$ of treatment (Figure 6).

\section{In vitro and in vivo bone surface affinity of the (Asp) $)_{8}$-PEG-PCL nanoparticles}

Intravenously administered (Asp) 8 -PEG-PCL showed higher accumulation in mouse femur and tibia (red color) in comparison to PEG-PCL (Figure 7A). Intravenously administered $\mathrm{CY} 7$ was almost unable to accumulate in bone

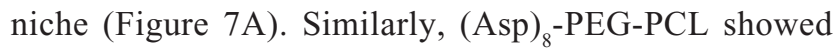
stronger affinity to hydroxyapatite in vitro at 2,7 , and $24 \mathrm{~h}$, compared to PEG-PCL (Figure 7B). The binding affinity of (Asp) $)_{8}$-PEG-PCL to hydroxyapatite was increased with increase in incubation time (Figure 7B). The highest affinity of the (Asp) $)_{8}$-PEG-PCL nanoparticles to hydroxyapatite was observed at $24 \mathrm{~h}$ of incubation (Figure 7B). (Asp) $)_{8}$-PEG-PCL nanoparticles showed almost 2 -fold higher affinity to hydroxyapatite compared to PEG-PCL at all the time points tested. This indicates bone-specific affinity of the (Asp) $)_{8}$-PEG-PCL nanoparticles.

In vivo binding affinity of intravenously administered coumarin-loaded (Asp) $)_{8}$-PEG-PCL on the bone surface is shown in Figure 7C and D. Free coumarin did not bind on the bone surface, but a faint green layer of coumarin-loaded PEG-PCL was observed on the bone surface (Figure 7D). A dark green layer of coumarin-loaded (Asp) ${ }_{8}$-PEG-PCL was observed on the bone surface (Figure 7D). Bonespecific affinity of coumarin-loaded (Asp) $)_{8}$-PEG-PCL was 2.7 times higher than that of coumarin-loaded PEG-PCL
(Figure 7C and D), which indicates the strong ability of intravenously administered (Asp) $)_{8}$-PEG-PCL to reach the bone niche and bind on the bone surface.

\section{Stability and curcumin loading and releasing affinity of the (Asp) $)_{8}-\mathrm{PEG}-\mathrm{PCL}$ nanoparticles}

An ideal nanoparticle as a drug carrier should load the drug in high amount and give sustained release of the loaded drug in appropriate dose. In this study, (Asp) ${ }_{8}$-PEG-PCL showed $11.07 \%$ curcumin loading efficiency (Table 1 ). The curcumin encapsulation efficiency of the (Asp) ${ }_{8}$-PEG-PCL nanoparticles was $95.91 \%$ (Table 1). The curcumin-loaded (Asp) ${ }_{8}^{-}$ PEG-PCL nanoparticles gave sustained release of curcumin for $>8$ days (Figure $8 \mathrm{~A}$ ). The amount of curcumin released from the curcumin-loaded (Asp) $)_{8}$-PEG-PCL nanoparticles was almost $50 \%$ less compared to curcumin released from dialysis bag containing native curcumin (Figure 8A).

Loading of curcumin did not affect the hydrodynamic diameter of (Asp) $)_{8}$-PEG-PCL nanoparticles in NS and fetal bovine serum till $48 \mathrm{~h}$ (Figure $8 \mathrm{~B}$ and $\mathrm{C}$ ). This indicates the stability of curcumin-loaded (Asp) ${ }_{8}$-PEG-PCL nanoparticles.

\section{In vitro antitumorigenic effect of the curcumin-loaded (Asp) ${ }_{8}$-PEG-PCL nanoparticles}

Native curcumin has strong anticancer properties, but it is still a challenge to use curcumin as anticancer therapy because native curcumin lacks solubility, stability, and bioavailability. Curcumin loaded in biopolymer nanoparticles usually has higher stability and water solubility. In this study, we found that curcumin-loaded (Asp) $)_{8}$-PEG-PCL has higher antitumorigenic effect on different cancer cell lines in vitro, 


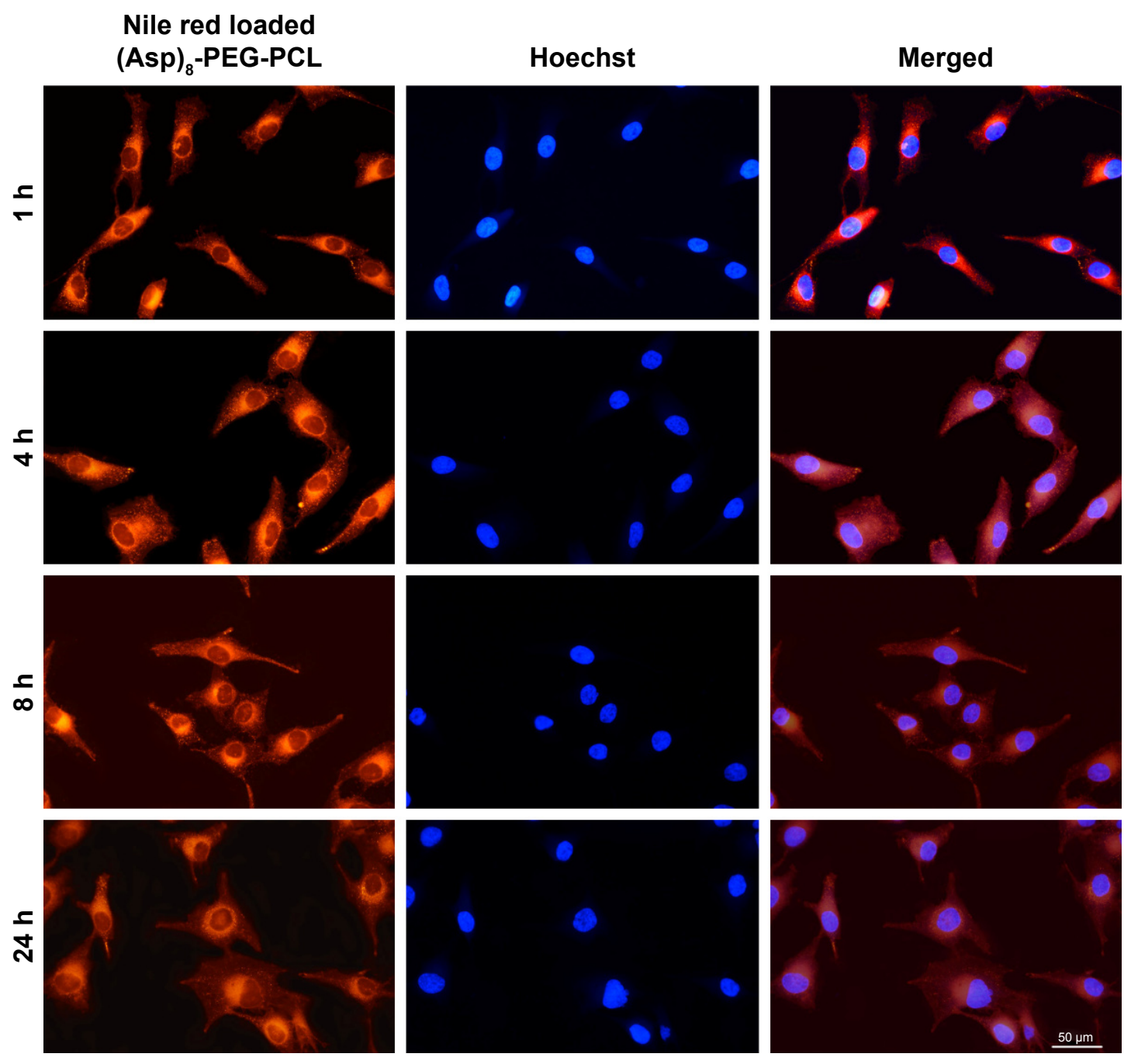

Figure 6 Fluorescence microscopic images of MG63 cells incubated with Nile red-loaded (Asp) ${ }_{8}-\mathrm{PEG}-\mathrm{PCL}$ nanoparticles at a concentration of $\mathrm{I} 00 \mu \mathrm{gg} / \mathrm{mL}$ at $37^{\circ} \mathrm{C}$. Cell nuclei were counterstained using Hoechst blue, and the blue and red fields of fluorescence images were merged at each time point.

Abbreviation: (Asp) ${ }_{8}$-PEG-PCL, polyaspartic acid peptides-poly (ethylene glycol)-poly ( $\varepsilon$-caprolactone) polymer.

in comparison to native curcumin (Figure 9A-C). Although the dose of curcumin released from (Asp) $)_{8}$-PEG-PCL nanoparticles is less than the dose available from native curcumin (Figure 8), curcumin-loaded (Asp) 8 -PEG-PCL showed higher antitumorigenic effect in comparison to native curcumin in vitro (Figure 9A-C).

\section{Discussion}

Hydrophobic anticancer drug delivery targeting the cancer metastasized to bone is a challenge due to poor solubility, bioavailability, instability, and lack of bone specificity of the drug. We synthesized and characterized the bonespecific (Asp) $)_{8}$-PEG-PCL copolymer as a hydrophobic anticancer curcumin carrier to treat the cancer metastasized to bone. (Asp) $)_{8}$-PEG-PCL copolymer was biocompatible, nonhemolytic, permeable in cells, a potent carrier, and an efficient releaser of curcumin and was bone specific Furthermore, curcumin-loaded (Asp) - $_{8}$-PEG-PCL copolymer showed strong antitumorigenic property in vitro. Therefore, (Asp)_-PEG-PCL copolymer could be a potent hydrophobic anticancer drug carrier to treat the cancer metastasized to bone.

Nanoparticles designed for hydrophobic drug delivery should have hydrophilic surface, hydrophobic core, and optimal size. ${ }^{40}$ Such nanoparticles should be large enough to prevent their rapid leakage into blood capillaries, but small enough to escape the capture by macrophages in the reticuloendothelial system. ${ }^{41}$ Bone-targeting nanoparticles should be $70-200 \mathrm{~nm}$ in size to reach the bone tissues by passing through the vascular structures and live organs of interest. $^{42}$ (Asp) $)_{8}$-PEG-PCL nanoparticles designed in this study had the hydrophilic surface of PEG and the hydrophilic 


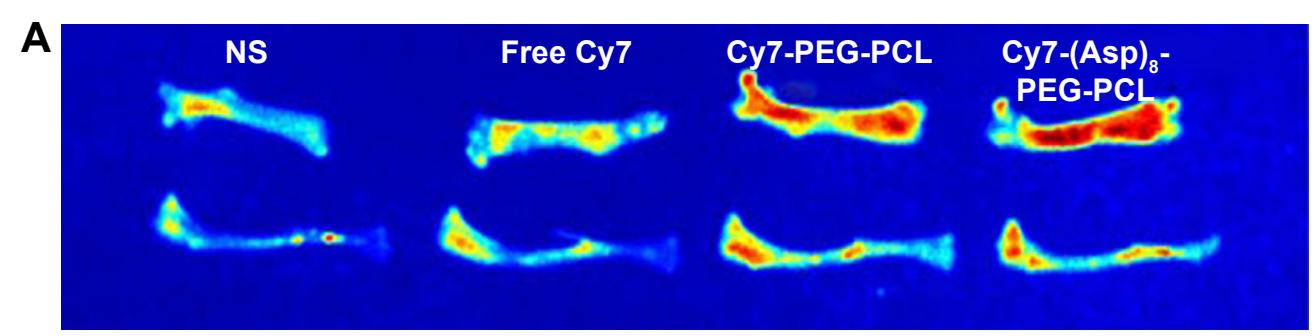

B

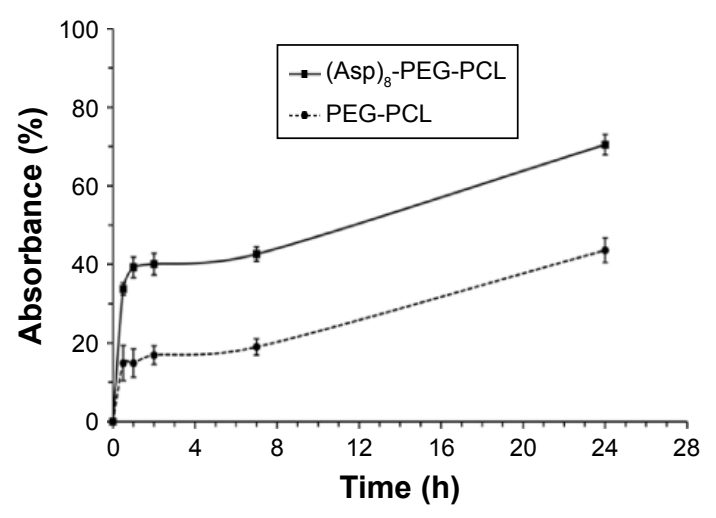

C

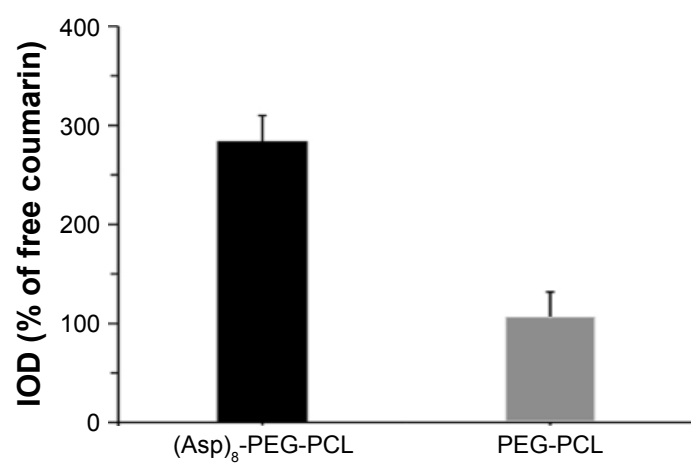

\section{D}
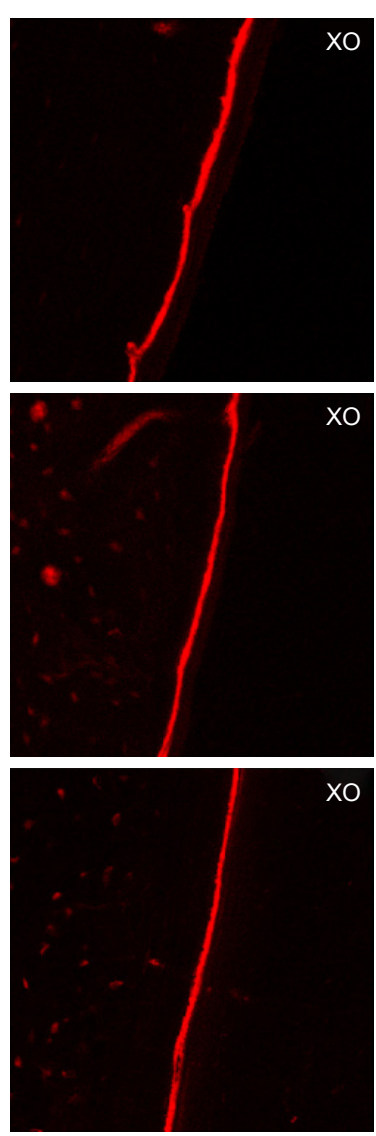
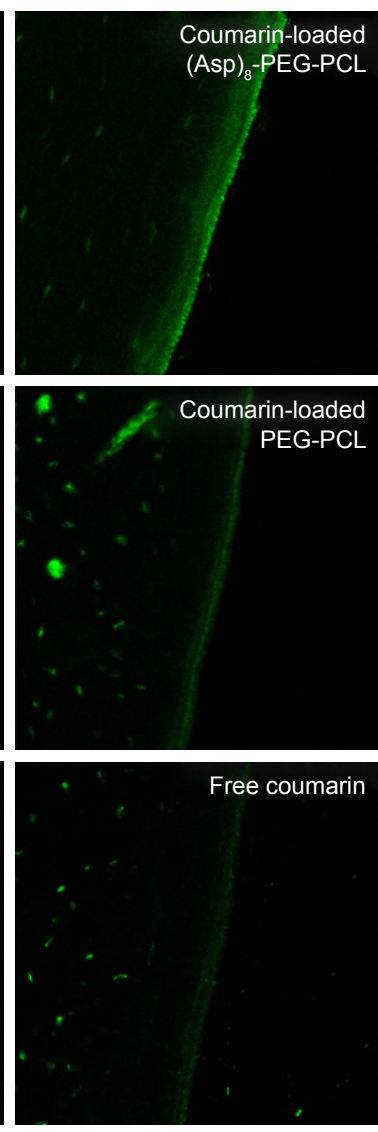
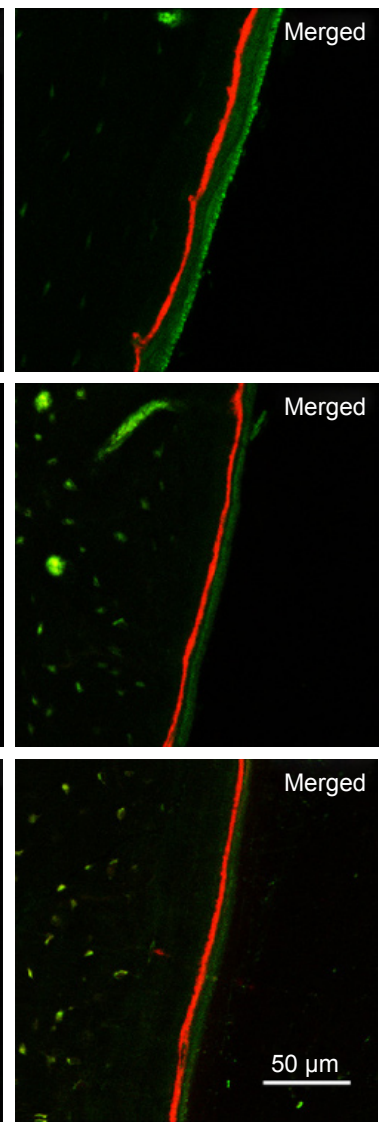

Figure 7 In vitro and in vivo bone specificity of the (Asp) $)_{8}-\mathrm{PEG}-\mathrm{PCL}$ nanoparticles.

Notes: (A) Fluorescence images showing accumulation of free Cy7, Cy7-PEG-PCL, or Cy7-(Asp) -PEG-PCL in mice femur and tibia. (B) Affinity to hydroxyapatite in vitro. (C) Quantification of coumarin-loaded (Asp) $)_{8}$-PEG-PCL and PEG-PCL deposited on the frontal tibial bone surface. (D) Confocal images of histologic sections of frontal tibia showing binding of $\mathrm{XO}$ and coumarin-loaded nanoparticles. $\mathrm{XO}$ in red color; coumarin or coumarin-loaded nanoparticles in green color.

Abbreviations: (Asp) $)_{8}$-PEG-PCL, polyaspartic acid peptides-poly (ethylene glycol)-poly (E-caprolactone) polymer; IOD, integrated optical density; NS, normal saline; PEG-PCL, poly (ethylene glycol)-poly ( $\varepsilon$-caprolactone) polymer. 
Table I Curcumin loading capacity and encapsulation efficiency of the (Asp) ${ }_{8}$-PEG-PCL

\begin{tabular}{lllllll}
\hline Experiment & $\begin{array}{l}\text { Total curcumin } \\
(\mathbf{m g})\end{array}$ & $\begin{array}{l}\text { Total }(\mathbf{A s p})_{8}{ }^{-} \\
\text {PEG-PCL }(\mathbf{m g})\end{array}$ & $\begin{array}{l}\text { Curcumin loaded in } \\
(\mathbf{A s p})_{8} \text {-PEG-PCL }(\mathbf{m g})\end{array}$ & $\begin{array}{l}\text { Encapsulation } \\
\text { efficiency }(\%)\end{array}$ & $\begin{array}{l}\text { Dried particle } \\
\text { weight }(\mathbf{m g})\end{array}$ & $\begin{array}{l}\text { Loading } \\
\text { capacity }(\%)\end{array}$ \\
\hline 1 & 2 & 20 & 1.844 & 92.209 & 17.511 & 10.531 \\
2 & 2 & 20 & 1.943 & 97.129 & 18.012 & 10.784 \\
3 & 2 & 20 & 1.967 & 98.394 & 16.532 & 11.903 \\
Mean & 2 & 20 & 1.918 & 95.911 & 17.351 & 11.073
\end{tabular}

Abbreviation: (Asp)-PEG-PCL, polyaspartic acid peptides-poly (ethylene glycol)-poly ( $\varepsilon$-caprolactone) polymer.

core of PCL with an average diameter of $100 \mathrm{~nm}$. Therefore, (Asp) ${ }_{8}$-PEG-PCL can be administered intravenously targeting the bone niche. Interestingly, (Asp) $)_{8}$-PEG-PCL nanoparticles were easily taken up by the cancer cells in vitro. Our findings indicate that the size and surface morphology of (Asp) $)_{8}$-PEG-PCL nanoparticles are suitable to reach the cancer cells in bone niche.

The effect of nanoparticles on erythrocyte aggregation indicates hemocompatibility of the nanoparticles. ${ }^{43}$ Copolymer containing PEG-PCL has been reported to be hemocompatible and biocompatible. ${ }^{44,45}$ In this study, we found that (Asp) $)_{8}$-PEG-PCL nanoparticles were hemocompatible, and biocompatible to osteoblasts and endothelial cells. Both polyaspartic acid peptides and PEG-PCL copolymer are reported as biocompatible to osteoblasts. ${ }^{44,46}$ In this study, linking (Asp) ${ }_{8}$ with the PEG-PCL copolymer did not affect the hemocompatibility and biocompatibility of the PEG-PCL copolymer. Nanoparticles designed to treat cancer metastasized to bone should have bone-specific affinity. Once administered intravenously, the bone-specific nanoparticles should be able to accumulate in the bone compartment. Polyaspartic acid peptide-linked nanoparticles showed strong bone-specific affinity both in vitro and in vivo. ${ }^{35,42}$ In this study, (Asp) $)_{8}$-PEG-PCL nanoparticles showed similar
A

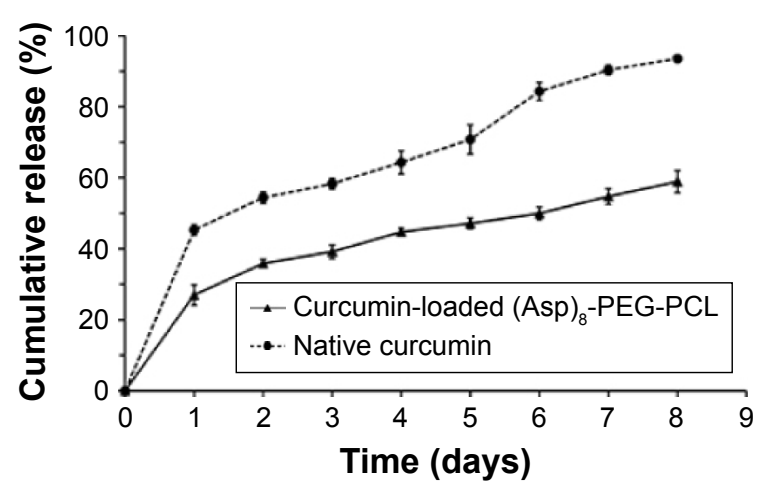

B

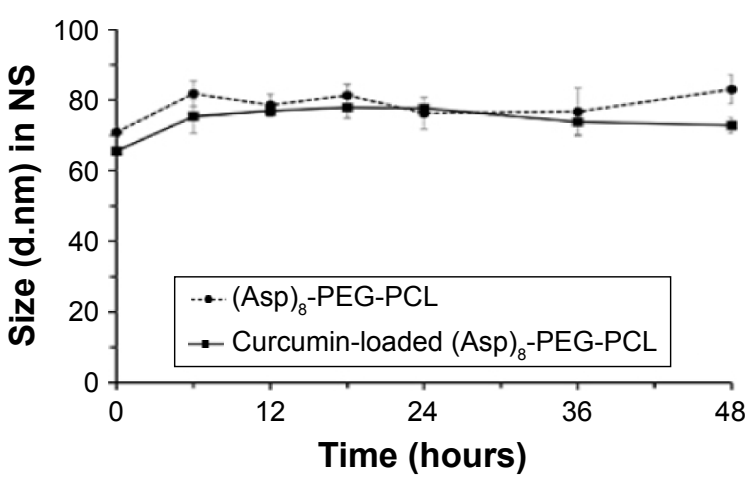

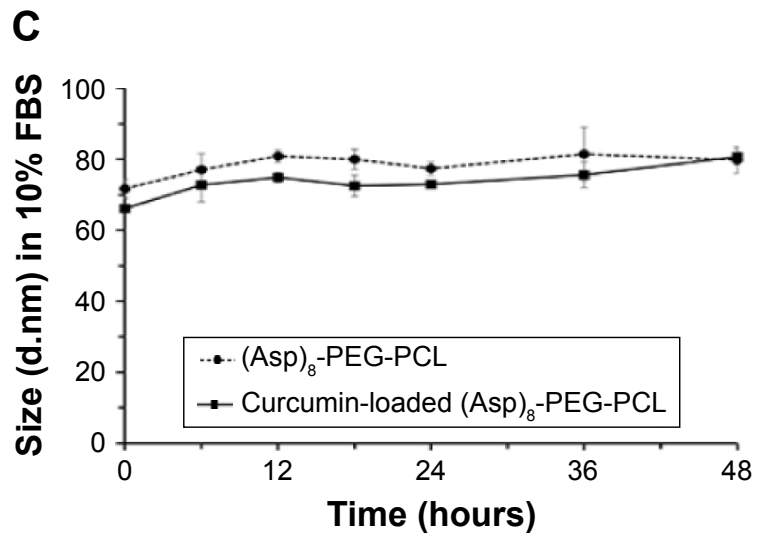

Figure 8 Curcumin releasing capacity and stability of curcumin loaded (Asp) $)_{8}$-PEG-PCL nanoparticles.

Notes: (A) In vitro release profiles of curcumin from curcumin-loaded (Asp) $)_{8}-\mathrm{PEG}-\mathrm{PCL}$ and dialysis bag containing native curcumin and in $\mathrm{PBS}$ solution ( $\left.\mathrm{pH}=7.4\right)$ at $37^{\circ} \mathrm{C}$. Stability of curcumin-loaded (Asp) $)_{8}$-PEG-PCL in (B) NS and (C) FBS.

Abbreviations: (Asp) ${ }_{8}$-PEG-PCL, polyaspartic acid peptides-poly (ethylene glycol)-poly ( $\varepsilon$-caprolactone) polymer; FBS, fetal bovine serum; NS, normal saline; PBS, phosphate-buffered saline. 

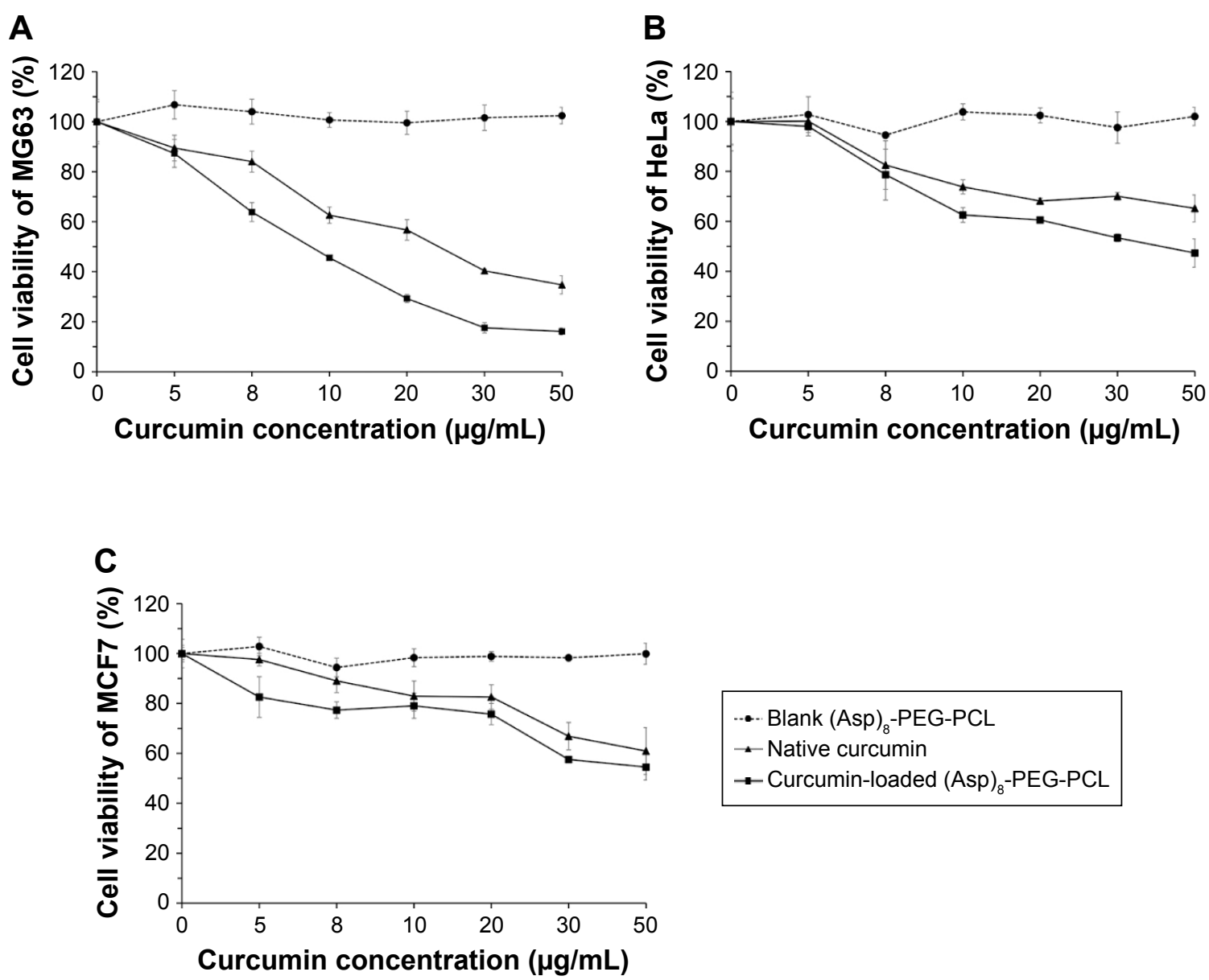

Figure 9 In vitro antitumorigenic effect of blank (Asp) ${ }_{8}$-PEG-PCL nanoparticles, native curcumin, and curcumin-loaded (Asp) ${ }_{8}$-PEG-PCL nanoparticles in different cancer cells: (A) osteosarcoma cells-MG63, (B) cervical cancer cells-HeLa, and (C) breast cancer cells-MCF7.

Abbreviation: (Asp) $)_{8}$-PEG-PCL, polyaspartic acid peptides-poly(ethylene glycol)-poly(e-caprolactone) polymer.

binding affinity to hydroxyapatite in vitro, as reported in previous studies using polyaspartic acid peptide-linked nanoparticles. ${ }^{35,42}$ Intravenously administered (Asp) 8 -PEGPCL and PEG-PCL nanoparticles were able to reach the bone niche; due to bone surface specificity of the (Asp) ${ }_{8}$-PEG-PCL nanoparticles, they accumulated in higher amount in comparison to the PEG-PCL nanoparticles. Interestingly, in vivo bone surface binding affinity of (Asp) $)_{8}$-PEG-PCL was stronger (2.8-fold) than that of (Asp) ${ }_{3}$-PEG-PLGA nanoparticles (1.5-fold) reported previously. ${ }^{42}$ Therefore, (Asp) $)_{8}$-PEG-PCL nanoparticles are safe and more effective to administer intravenously targeting remote bone niche, compared to bone-targeting nanoparticles designed previously.

PEG-PCL copolymer contains hydrophilic PEG surface and hydrophobic PCL core. ${ }^{11-13}$ Hydrophobic drugs can be easily incorporated into the core of (Asp) ${ }_{8}$-PEG-PCL by covalent or noncovalent bonding through hydrophobic interactions in aqueous media. ${ }^{44,47} \mathrm{We}$ found that hydrophobic anticancer curcumin was efficiently loaded and encapsulated

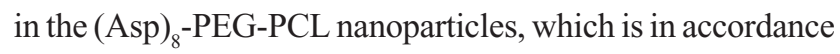
with the findings from the literature reports. ${ }^{39,44}$ Moreover, (Asp) $)_{8}$-PEG-PCL nanoparticles gave sustained release of curcumin for $>8$ days. Although the dose of released curcumin from (Asp) $)_{8}$-PEG-PCL nanoparticles was less than that of native curcumin, the curcumin-loaded (Asp) ${ }_{8}$-PEG-PCL enhanced cancer cell death compared to native curcumin. Our finding is strongly supported by the data reported by Li et al showing that the curcumin loaded in amphiphilic nanoparticles enhances the antitumorigenic effect of curcumin when compared to native curcumin. ${ }^{39}$ This suggests that linking (Asp) 8 with PEG-PCL nanoparticles did not affect the curcumin loading, encapsulating, and releasing capacity of PEG-PCL nanoparticles. Due to the limitations related to native curcumin and PEG-PCL copolymer, we propose the curcumin-loaded (Asp) - $_{8}$-PEG-PCL as a potent therapeutic model to treat cancer metastasized to bone. However, further in vivo and preclinical studies are needed to evaluate this hypothesis. 
Curcumin has anticancer, anti-inflammatory, antioxidant, and wound healing properties. ${ }^{11}$ Cancer bone metastasis inhibits osteoblast differentiation and enhances osteoclast formation and activity, which causes osteolysis. ${ }^{48}$ Cancer bone metastasis induces an osteoblast inflammatory response, and this disturbs bone homeostasis. ${ }^{48}$ Disrupted bone homeostasis accelerates cancer cell propagation during cancer bone metastasis. Excessive bone loss and bone-related complications are the main concerns during cancer bone metastasis. In this study, intravenously administered curcumin-loaded (Asp) $)_{8}$-PEG-PCL was highly accumulated in the bone surface. Curcumin has not only anticancer but also bone anabolic properties. ${ }^{28}$ Curcumin enhances bone-forming "osteoblast" differentiation, and the curcumin analog inhibits boneresorbing "osteoclast" formation. ${ }^{49}$ Therefore, curcumin released from (Asp) $)_{8}$-PEG-PCL might kill the cancer cells metastasized in bone niche, as well as maintain bone homeostasis and inhibit osteolysis. Furthermore, curcumin-loaded (Asp) - $_{8}$-PEG-PCL might also be useful for bone regeneration and osteoporosis treatment.

Curcumin combined with another hydrophobic anticancer drug "etoposide" disturbs the crosstalk between cancer cell and osteoblasts. ${ }^{50}$ Therefore, (Asp) ${ }_{8}$-PEG-PCL nanoparticles can be used as a carrier of multiple hydrophobic anticancer drugs having synergistic anticancer effect and bone anabolic effect, such as curcumin and etoposide. However, further studies are needed to test this hypothesis. The curcuminloaded (Asp) $)_{8}$-PEG-PCL nanoparticles might also be a potential treatment approach for osteosarcoma, since curcumin shows selective cytotoxicity against MG63 osteosarcoma cells when compared with normal osteoblasts. ${ }^{51}$ In this study, the combination of three components with unique properties, that is, 1) the bone-specific affinity of the (Asp) ${ }_{8}$, 2) hydrophobic anticancer drug-carrying ability of the PEGPCL, and 3) the anticancer and bone anabolic properties of curcumin, makes the curcumin-loaded (Asp) ${ }_{8}$-PEG-PCL nanoparticles a potent therapeutic model to treat the cancer metastasized to bone.

\section{Conclusion}

(Asp) $)_{8}$-PEG-PCL nanoparticles were biocompatible, easily permeable in cells, bone specific, and a potent carrier and efficient releaser of hydrophobic drugs. Intravenously injected (Asp) $)_{8}$-PEG-PCL nanoparticles were able to accumulate in the bone niche. Linking (Asp) ${ }_{8}$ with PEGPCL nanoparticles robustly enhanced the in vivo bone affinity. Hydrophobic anticancer curcumin-loaded (Asp) ${ }_{8}$ PEG-PCL nanoparticles showed strong antitumorigenic ability in vitro. Therefore, bone-specific (Asp) $)_{8}$-PEG-PCL nanoparticles hold great potential for clinical application in delivering hydrophobic anticancer drugs to the bone niches, targeting the cancer metastasized to bone. Results of this study provide prerequisites to test in vivo the antitumorigenic potential of hydrophobic anticancer drugloaded (Asp) ${ }_{8}$-PEG-PCL in animal models with cancer metastasized to bone.

\section{Acknowledgments}

The authors would like to acknowledge the support provided by the Nature Science Foundation of Zhejiang Province (No LY13H140005), the National Natural Science Foundation of China (No 81371182 and No 81271186), Zhejiang Provincial Science and Technology Project for Public Welfare (No 2015C33139), and Wenzhou Municipal Science and Technology Project for Public Welfare (No Y20150074).

\section{Author contributions}

All authors contributed toward data analysis, drafting and critically revising the paper and agree to be accountable for all aspects of the work.

\section{Disclosure}

The authors report no conflicts of interest in this work.

\section{References}

1. Roodman GD. Mechanisms of bone metastasis. N Engl J Med. 2004; 350(16):1655-1664.

2. Clark PE, Torti FM. Prostate cancer and bone metastases: medical treatment. Clin Orthop. 2003;415:S148-S157.

3. Mundy GR. Metastasis to bone: causes, consequences and therapeutic opportunities. Nat Rev Cancer. 2002;2(8):584-593.

4. Guise TA, Mundy GR. Cancer and bone. Endocr Rev. 1998;19(1): 18-54.

5. Chen YC, Sosnoski DM, Mastro AM. Breast cancer metastasis to the bone: mechanisms of bone loss. Breast Cancer Res. 2010;12(6):215.

6. Bubendorf L, Schopfer A, Wagner U, et al. Metastatic patterns of prostate cancer: an autopsy study of 1,589 patients. Hum Pathol. 2000; 31(5):578-583.

7. Psaila B, Lyden D. The metastatic niche: adapting the foreign soil Nat Rev Cancer. 2009;9(4):285-293.

8. Domchek SM, Younger J, Finkelstein DM, Seiden MV. Predictors of skeletal complications in patients with metastatic breast carcinoma. Cancer. 2000;89(2):363-368.

9. Chaudhari KR, Kumar A, Khandelwal VK, et al. Bone metastasis targeting: a novel approach to reach bone using zoledronate anchored PLGA nanoparticle as carrier system loaded with docetaxel. J Control Release. 2012;158(3):470-478.

10. Jamal SA, Ljunggren O, Stehman-Breen C, et al. Effects of denosumab on fracture and bone mineral density by level of kidney function. $J$ Bone Miner Res. 2011;26(8):1829-1835.

11. Xue B, Wang Y, Tang XH, et al. Biodegradable self-assembled MPEG-PCL nanoparticles for hydrophobic oridonin delivery in vitro. J Biomed Nanotechnol. 2012;8(1):80-89. 
12. Gong $\mathrm{C}$, Deng $\mathrm{S}, \mathrm{Wu} \mathrm{Q}$, et al. Improving antiangiogenesis and antitumor activity of curcumin by biodegradable polymeric nanoparticles. Biomaterials. 2013;34(4):1413-1432.

13. Duan XM, Wang P, Men K, et al. Treating colon cancer with a suicide gene delivered by self-assembled cationic MPEG-PCL nanoparticles. Nanoscale. 2012;4(7):2400-2407.

14. Shi S, Zhu X, Guo Q, et al. Self-assembled mPEG-PCL-g-PEI nanoparticles for simultaneous codelivery of chemotherapeutic drugs and DNA: synthesis and characterization in vitro. Int J Nanomedicine. 2012;7: 1749-1759.

15. Wang HM, Liu J, Tao S, et al. Tetracycline-grafted PLGA nanoparticles as bone-targeting drug delivery system. Int J Nanomedicine. 2015;10(1): 5671-5685.

16. Cheng TL, Murphy CM, Ravarian R, et al. Bisphosphonate-adsorbed ceramic nanoparticles increase bone formation in an injectable carrier for bone tissue engineering. J Tissue Eng. 2015;6:2041731415609448.

17. Miller S, Pan H, Wang D, Bowman B, Kopecková P, Kopecek J. Feasibility of using a bone-targeted, macromolecular delivery system coupled with prostaglandin E1 to promote bone formation in aged, estrogen-deficient rats. Pharm Res. 2008;25(12):2889-2895.

18. Imazrooa SA, Woo S. Bisphosphonate and nonbisphosphonateassociated osteonecrosis of the jaw: a review. J Am Dent Assoc. 2009; 140(7):864-875

19. Ouyang L, Huang W, He G, Guo L. Bone targeting prodrugs based on peptide dendrimers, synthesis and hydroxyapatite binding in vitro. Lett Org Chem. 2009;6(4):272-277.

20. Ogawa K, Ishizaki A, Takai K, et al. Development of novel radiogallium-labeled bone imaging agents using oligo-aspartic acid peptides as carriers. PLoS One. 2013;8(12):e84335.

21. Wang D, Miller SC, Shlyakhtenko LS, et al. Osteotropic peptide that differentiates functional domains of the skeleton. Bioconjug Chem. 2007; 18(5):1375-1378.

22. Wang D, Miller SC, Sima M, et al. Synthesis and evaluation of watersoluble polymeric bone-targeted drug delivery systems. Bioconjug Chem. 2003;14(5):853-859.

23. Holohan C, Van Schaeybroeck S, Longley DB, Johnston PG. Cancer drug resistance: an evolving pradigm. Nat Rev Cancer. 2013;13(10): 714-726.

24. Gupta SC, Patchva S, Koh W, Aggarwal BB. Discovery of curcumin, a component of golden spice, and its miraculous biological activities. Clin Exp Pharmacol Physiol. 2012;39(3):283-299.

25. Lin SS, Lai KC, Hsu SC, et al. Curcumin inhibits the migration and invasion of human A549 lung cancer cells through the inhibition of matrix metalloproteinase-2 and -9 and vascular endothelial growth factor (VEGF). Cancer Lett. 2009;285(2):127-133.

26. Anuchapreeda S, Thanarattanakorn P, Sittipreechacharn S, Tima S, Chanarat P, Limtrakul P. Inhibitory effect of curcumin on MDR1 gene expression in patient leukemic cells. Arch Pharm Res. 2006;29(10): 866-873.

27. Kunnumakkara AB, Anand P, Aggarwal BB. Curcumin inhibits proliferation, invasion, angiogenesis and metastasis of different cancers through interaction with multiple cell signaling proteins. Cancer Lett. 2008;269(2):199-225.

28. Rohanizadeh R, Deng Y, Verron E. Therapeutic actions of curcumin in bone disorders. Bonekey Rep. 2016;5:793.

29. Suwannateep N, Banlunara W, Wanichwecharungruang SP, Chiablaem K, Lirdprapamongkol K, Svasti J. Mucoadhesive curcumin nanospheres: biological activity, adhesion to stomach mucosa and release of curcumin into the circulation. J Control Release. 2011;151(2):176-182.

30. Rejinold NS, Sreerekha PR, Chennazhi KP, Nair SV, Jayakumar R. Biocompatible, biodegradable and thermo-sensitive chitosan-g-poly (N-isopropylacrylamide) nanocarrier for curcumin drug delivery. Int J Biol Macromol. 2011;49(2):161-172.
31. Yallapu MM, Jaggi M, Chauhan SC. Beta-Cyclodextrin-curcumin self-assembly enhances curcumin delivery in prostate cancer cells. Colloid Surf B Biointerfaces. 2010;79(1):113-125.

32. Rejinold NS, Muthunarayanan M, Divyarani VV, et al. Curcuminloaded biocompatible thermoresponsive polymeric nanoparticles for cancer drug delivery. J Colloid Interface Sci. 2011;360(1):39-51.

33. ASTM Standard. Standard practice for assessment of hemolytic properties of materials. Tech Rep. 2008;F756-08.

34. Danafar H, Sharafi A, Manjili HK, et al. Sulforaphane delivery using mPEG-PCL co-polymer nanoparticles to breast cancer cells. Pharma Dev Technol. 2016;25:1-10.

35. Fu Y, Fu T, Wang H, et al. Aspartic acid-based modified PLGA-PEG nanoparticles for bone targeting: in vitro and in vivo evaluation. Acta Biomater. 2014;10(11):4583-4596.

36. Stuart AJ, Smith DA. Use of the fluorochromes xylenol orange, calcein green, and tetracycline to document bone deposition and remodeling in healing fractures in chickens. Avian Dis. 1992;36(2):447-449.

37. Kasugai S, Fujisawa R, Waki Y, et al. Selective drug delivery system to bone: small peptide (Asp)6 conjugation. J Bone Miner Res. 2000; 15(5):936-943.

38. Gou ML, Men K, Shi HS, et al. Curcumin-loaded biodegradable polymeric nanoparticles for colon cancer therapy in vitro and in vivo. Nanoscale. 2012;3(4):1558-1567.

39. Li X, Chen T, Xu L, et al. Preparation of curcumin nanoparticles and the in vitro and in vivo evaluation for cancer therapy. $J$ Biomed Nanotechnol. 2014;10(8):1458-1468.

40. Owens DE, Peppas NA. Opsonization, biodistribution, and pharmacokinetics of polymeric nanoparticles. Int J Pharm. 2006;307(1):93-102.

41. Wisse E, Braet F, Luo D, et al. Structure and function of sinusoidal lining cells in the liver. Toxicol Pathol. 1996;24(1):100-111.

42. Fu YC, Fu TF, Wang HJ, et al. Aspartic acid-based modified PLGAPEG nanoparticles for bone targeting: in vitro and in vivo evaluation. Acta Biomater. 2014;10(11):4583-4596.

43. Chen LQ, Fang L, Ling J, Ding CZ, Kang B, Huang CZ. Nanotoxicity of silver nanoparticles to red blood cells: size dependent adsorption, uptake, and hemolytic activity. Chem Res Toxicol. 2015;28(3):501-509.

44. Wei X, Gong C, Gou M, et al. Biodegradable poly (epsilon-caprolactone)poly (ethylene glycol) copolymers as drug delivery system. Int J Pharm. 2009;381(1):1-18.

45. Shi S, Shi K, Tan L, et al. The use of cationic MPEG-PCL-g-PEI nanoparticles for co-delivery of Msurvivin T34A gene and doxorubicin. Biomaterials. 2014;35(15):4536-4547.

46. Hou J, Fan D, Zhao L, et al. Degradability, cytocompatibility, and osteogenesis of porous scaffolds of nanobredigite and PCL-PEG-PCL composite. Int J Nanomedicine. 2016;11:3545-3555.

47. Gou M, Wei X, Men K, et al. PCL/PEG copolymeric nanoparticles: potential nanoplatforms for anticancer agent delivery. Curr Drug Targets. 2011;12(8):1131-1150.

48. Kinder M, Chislock EM, Bussard KM, et al. Metastatic breast cancer induces an osteoblast inflammatory response. Exp Cell Res. 2008;314(1): 173-183.

49. Yamaguchi M, Moore TW, Sun A, Snyder JP, Shoji M. Novel curcumin analogue UBS109 potently stimulates osteoblastogenesis and suppresses osteoclastogenesis: involvement in Smad activation and NF-кB inhibition. Integr Biol (Camb). 2012;4(8):905-913.

50. Shukla P, Mathur, Kumar A, et al. Nanoemulsion based concomitant delivery of curcumin and etoposide: impact on cross talk between prostate cancer cells and osteoblast during metastasis. J Biomed Nanotechnol. 2014;10(11):3381-3391.

51. Chang R, Sun L, Webster TJ. Short communication: selective cytotoxicity of curcumin on osteosarcoma cells compared to healthy osteoblasts. Int J Nanomedicine. 2014;9(1):461-465. 
International Journal of Nanomedicine

Dovepress

\section{Publish your work in this journal}

The International Journal of Nanomedicine is an international, peerreviewed journal focusing on the application of nanotechnology in diagnostics, therapeutics, and drug delivery systems throughout the biomedical field. This journal is indexed on PubMed Central, MedLine, CAS, SciSearch ${ }^{\circledR}$, Current Contents ${ }^{\circledR} /$ Clinical Medicine,
Journal Citation Reports/Science Edition, EMBase, Scopus and the Elsevier Bibliographic databases. The manuscript management system is completely online and includes a very quick and fair peer-review system, which is all easy to use. Visit http://www.dovepress.com/ testimonials.php to read real quotes from published authors.

Submit your manuscript here: http://www.dovepress.com/international-journal-of-nanomedicine-journal 